14.1;06.5;05.1

\title{
Модель развития микротрещин в дентине зубов человека на основе данных микротомографии
}

\author{
(C) T.С. Аргунова ${ }^{1}$, Ж.В. Гудкина ${ }^{1,2}$, М.Ю. Гуткин ${ }^{2-4}$ \\ ${ }^{1}$ Физико-технический институт им. А.Ф. Иофффе РАН, Санкт-Петербург, Россия \\ ${ }^{2}$ Санкт-Петербургский политехнический университет Петра Великого, Санкт-Петербург, Россия \\ ${ }^{3}$ Институт проблем машиноведения РАН, Санкт-Петербург, Россия \\ ${ }^{4}$ Университет ИТМО, Санкт-Петербург, Россия \\ E-mail: argunova@mail.ioffe.ru
}

Поступило в Редакцию 2 марта 2020 г.

В окончательной редакции 2 марта 2020 г.

Принято к публикации 3 марта 2020г.

Особенностью структуры дентина являются микроканалы, которые пронизывают матрицу, сформированную коллагеновыми волокнами и нанокристаллами гидроксиапатита. Изучено влияние микроканалов на трещиностойкость дентина. Образцы, приготовленные из моляров человека, были подвергнуты одноосному сжатию до появления трещин и затем исследованы методом микротомографии в синхротронном излучении. Полученные результаты позволили разработать модель развития микротрещин поперечного сдвига в дентине.

Ключевые слова: дентин, микроканалы, прочность, рентгеновская микротомография.

DOI: 10.21883/PJTF.2020.10.49433.18268

Дентин - это легкий, но очень прочный материал. В процессе деформации он способен поглощать большую механическую энергию, что защищает зубы от разрушения. Высокая ударная вязкость дентина обусловлена присутствием в нем сетки волокон, состоящих из природного белка коллагена и упрочненных нанокристаллами гидроксиапатита [1]. Роль коллагена в торможении трещин объясняет эмпирическая модель [2], согласно которой между краями трещины образуются мостики из волокон, которые стягивают ее берега, и в результате трещина развивается в режиме бриджинга.

Наличие в дентине составляющих разного масштабного уровня - от наноскопических волокон коллагена до дентинных каналов (ДК) микроскопического диаметра - позволяет рассматривать его как иерархический композит [1]. Механическое поведение природных композитов и механизмы, которые определяют это поведение, вызывают большой интерес $[1,2]$. В частности, это касается поведения дентина при разрушении [1-3].

Механические свойства дентина анизотропны, потому что коллагеновые волокна распределены неравномерно. Так, существенно отличаются значения модуля Юнга вдоль $(\sim 13 \mathrm{GPa})$ и поперек $(\sim 5-6 \mathrm{GPa})$ ДК [1]. Вязкость разрушения выше для трещин, распространяющихся в плоскости, параллельной ДК $\left(2.4-2.6 \mathrm{MPa} \cdot \mathrm{m}^{1 / 2}\right)$, чем для трещин, растущих в плоскости, перпендикулярной ДК $\left(1.6 \mathrm{MPa} \cdot \mathrm{m}^{1 / 2}\right)[2]$.

Проблема, однако, заключается в том, что при механическом испытании, будь то изгиб [2], имитация окклюзионной нагрузки [4] или ультразвуковые колебания [5], нагружению подвергается весь объем образца, тогда как ориентацию ДК определяют на основе наблюдений внешней поверхности. Это приводит к несовпадению данных разных авторов [4,5]. Тем не менее общепризнанно, что высокие значения прочности и трещиностойкости дентина объясняются действием таких механизмов, как зарождение сателлитных трещин перед вершиной магистральной трещины и бриджинг трещин связками из неразорвавшихся волокон коллагена.

Другим известным механизмом диссипации энергии в вершинах трещин, растущих в дентине, является их отклонение от начального направления роста [2]. Эффект отклонения был подтвержден наблюдениями пересечения траекторий трещин с ДК [3]. Однако объяснения механизма взаимодействия трещин с ДК не предложено до сих пор.

Настоящая работа акцентирует внимание на роли ДК в механизмах диссипации энергии в вершинах растущих трещин путем их отклонения и ветвления с образованием сателлитных трещин. Для наблюдения микроструктуры образцов использован метод рентгеновской микротомографии с расширенными функциональными возможностями.

Рентгеновская томография - это метод реконструкции плотности поглощения в поперечных сечениях по высоте образца из экспериментальных изображений („проекций“), которые фиксируют интегральное ослабление пучка вдоль его направления. Проекции получают путем вращения образца вокруг вертикальной оси. Трехмерное (3D) изображение виртуального объекта формируют из поперечных сечений („томограмм“6) с использованием программ визуализации.

Источники синхротронного излучения (СИ) третьего поколения создают условия для регистрации рентгеновского фазового контраста, который позволяет обнаруживать элементы структуры размером меньше микрометра. 
Алгоритмы восстановления фазы в сочетании с алгоритмами реконструкции изображений разработаны лишь для простых микрообъектов (см., например, [6]). Коммерческие программы по томографии фазовый контраст не учитывают. На основании того, что для системы ДК в довольно толстом образце вклад контраста поглощения растет, а фазы усредняются, в настоящей работе была использована стандартная программа реконструкции изображений поглощающих объектов. Это позволило визуализировать направления ДК, потому что в ближнем поле существует соответствие между объектом и его изображением.

Изготовление и механические испытания образцов дентина [1] проводились в Уральском федеральном университете им. Б.Н. Ельцина с соблюдением этического протокола. Образцы были изготовлены из моляров, удаленных у пациентов по медицинским показаниям. Из корневых частей вырезались пластины длиной $D=4-5 \mathrm{~mm}$, шириной $W=2-3 \mathrm{~mm}$ и толщиной $H=0.3-0.5 \mathrm{~mm}$. Нарушенный слой удалялся посредством механической полировки без использования кислот. Испытания на одноосное сжатие при комнатной температуре проводились на разрывной машине Shimadzu AGX-50 kN с ориентацией оси нагружения вдоль толщины пластины.

Томографические эксперименты выполнялись на станции биомедицинской визуализации (6С) источника СИ Pohang Light Source в г. Поханге (Южная Корея). Для энергии монохроматического излучения $E=25 \mathrm{keV}$ длина поперечной когерентности составляла $31 \mu \mathrm{m}$ на расстоянии $36 \mathrm{~m}$ от источника. Оптический объектив $(\times 20)$ проецировал люминесцентное изображение от кристалла-сцинтиллятора YAG: Се на детектор с размером эффективных пикселей $0.3 \mu \mathrm{m}$. Проекции записывались с шагом $0.2^{\circ}$ в интервале поворота образца $0-180^{\circ}$. Для получения томограмм и реконструкции виртуальных 3D-объектов использовались компьютерные программы „Octopus 8.7“ и „Amira 5.4“ соответственно.

На рис. 1 приведено 3D-изображение образца дентина после двухэтапного сжатия до напряжений 280 и $370 \mathrm{MPa}$. Можно видеть, что в образце сформировалась область разрушения, охватывающая трещины, которые распространяются от края образца как вдоль его поверхности, так и в глубину. Направление номинального роста магистральной трещины в плоскости сечения $x y$, обозначенное на рисунке вектором $\mathbf{u}$, составляет угол $\sim 25^{\circ}$ с направлением нагрузки, приложенной вдоль оси $x$ (рис. $1, a)$. Вблизи поверхности трещина имеет максимальную длину $u \approx 420 \mu \mathrm{m}$. В направлении вектора $\mathbf{h}$, который коллинеарен оси $z$, длина трещины уменьшается с глубиной, в частности до $u \approx 290 \mu \mathrm{m}$ на глубине $h=208 \mu \mathrm{m}$. На глубине $h=300 \mu \mathrm{m}$ трещины практически не видны. На левой вставке к рис. 1, $a$ след магистральной трещины в плоскости сечения $y z$ показан волнистой линией. На правой вставке направление роста трещины в плоскости сечения $x z$ указано стрелкой, которая образует углы 60-65 с направлениями ДК, аппроксимированными прямыми линиями.

Вследствие эффекта анизотропии вязкости разрушения в дентине коэффициент интенсивности напряжений в вершине трещины на 55-65\% выше для трещин, прорастающих в плоскости, параллельной оси ДК, чем для трещин в перпендикулярной им плоскости $[1,2,5]$. Влиянием анизотропии можно объяснить распространение трещины на довольно большое расстояние $h=300 \mu \mathrm{m}$ в глубину образца (рис. 1,a). В перпендикулярном направлении и трещина быстро укорачивается.

На рис. $1, b$ показана та же область разрушения, что и на рис. $1, a$, но с другой стороны. Обратим внимание на то, что область разрушения имеет изогнутую форму. Поворот виртуального объекта при помощи программы визуализации выявляет веерообразное расположение ДК, которые расходятся из зоны „головки веера“, обозначенной буквой $F$. В другом ракурсе головка веера сместилась вдоль оси $y$ в левую часть рисунка, но изображение сохраняет связь между формой области разрушения и направлением ДК (рис. 1,c).

Как известно, ДК в дентине расходятся веером от пульповой камеры к периферии зуба. Можно предположить, что искривление плоской формы области разрушения обусловлено распространением трещин в направлениях, перпендикулярных ДК, из-за пониженной вязкости разрушения в этих направлениях. По мере того как ДК изменяют ориентацию в пределах „веера“, трещины так же изменяют свою траекторию, оставаясь перпендикулярными осям ДК.

Рассмотрим изменения области разрушения с глубиной. На рис. 2 показаны картины, которые построены с использованием техники объемного рендеринга из поперечных сечений $x y$, расположенных на разной глубине $h$. Для построения взято всего несколько сечений, разделенных расстоянием $0.3 \mu \mathrm{m}$. Рис. $2, a$ соответствует глубине $h=40 \mu \mathrm{m}$ от поверхности максимальных разрушений $(z=0)$. Магистральная трещина 1 , которая зародилась на левом краю образца, разветвляется на две сателлитные трещины (СТ) 2 и 3. Эти СТ снова сливаются в одну трещину 4, которая, не прекращая своего роста, испытывает локальные отклонения. На глубине $h=63 \mu \mathrm{m}$ магистральная трещина стала короче: положение ее вершины сместилось ближе к краю образца (рис. 2,b). СТ перед ее вершиной разделены более значительным расстоянием. На глубине $h=90 \mu \mathrm{m}$ (рис. 2,c) яснее проступает связь трещин с ДК. Некоторые ДК в следе СТ отмечены стрелками. Они расположены там, где СТ испытывают отклонение и расщепление. Группа СТ в верхней части изображения останавливается в неповрежденном дентине. С ростом $h$ процессы диссипации энергии в вершине магистральной трещины приводят к ее полной остановке на глубине $h=300 \mu \mathrm{m}$.

Для прояснения вопроса о роли ДК в зарождении, развитии и торможении трещин в дентине рассмотрим теоретическую модель, которая объясняет образование 

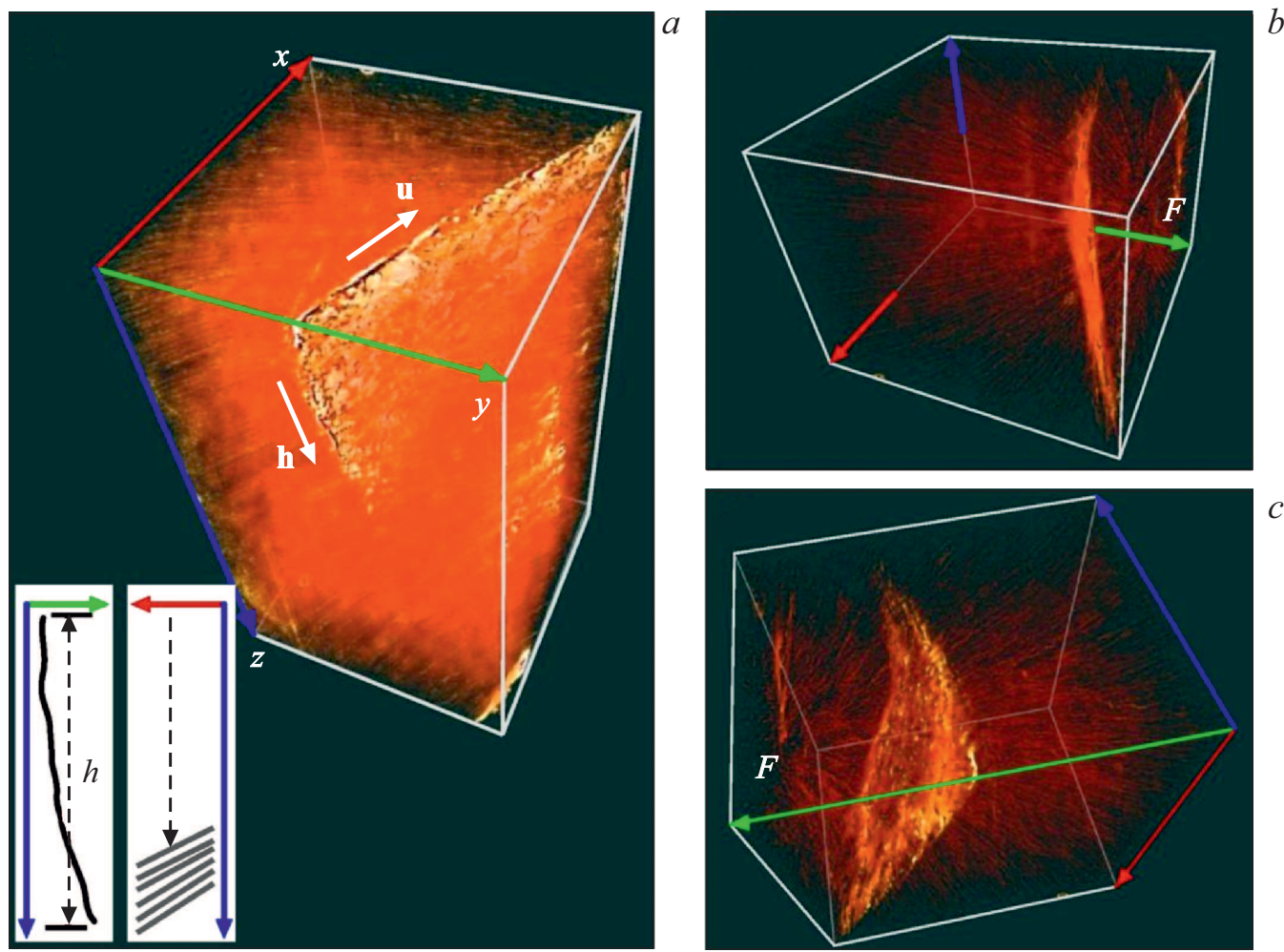

Рис. 1. Изображения $(a-c)$ образца дентина, реконструированные путем применения нескольких точек наблюдения. Область реконструкции имеет размеры $400 \times 390 \times 700 \mu \mathrm{m}$ вдоль осей $x, y$ и $z$ соответственно. На вставках показаны след трещины в сечении $y z(h=300 \mu$ m при $x=0)$ (слева) и направление роста трещины в сечении $x z$ относительно осей ДК (справа).
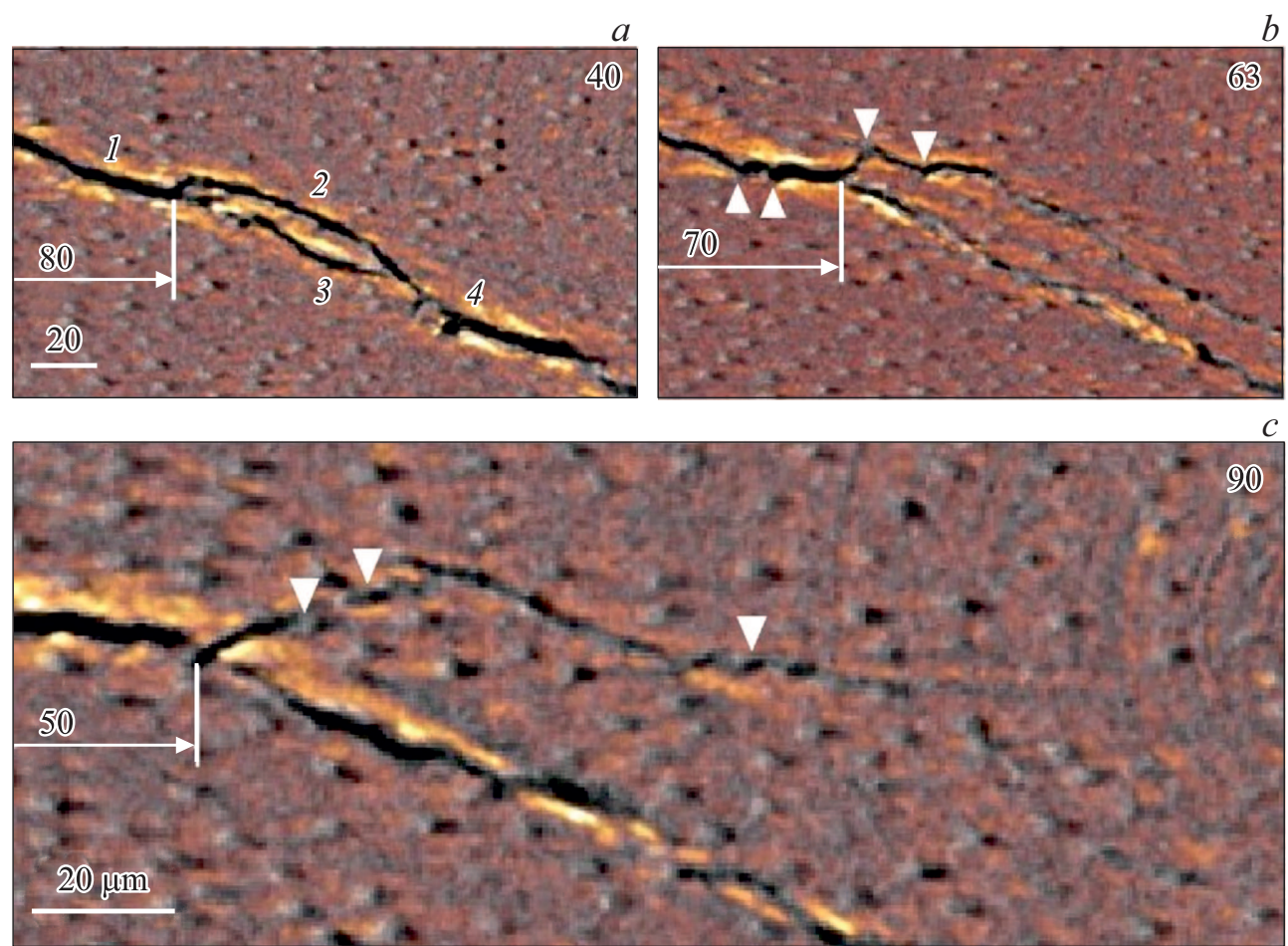

Рис. 2. Трещины и ДК в сечениях $x y$, расположенных на глубине $40(a), 63(b)$ и $90 \mu \mathrm{m}(c)$ от уровня $z=0.1-$ магистральная трещина (расстояние от вершины трещины 1 до края образца равно $80 \mu \mathrm{m}$ ), 2 и 3 - сателлитные трещины, слившиеся в трещину $4(a)$. На поле рисунка отмечены отклонения траекторий трещин $(b)$ и положения ДК $(c)$. 


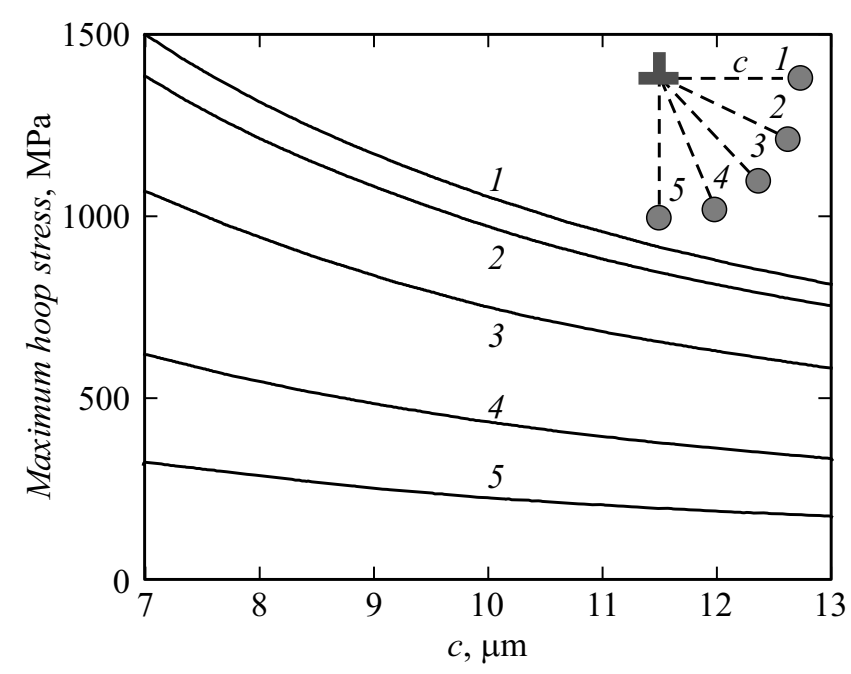

Рис. 3. Зависимости максимальных значений окружных напряжений на поверхности микроканала от его расстояния до вершины трещины при различных положениях микроканала. На вставке показано положение пробного микроканала относительно вершины трещины, которую моделирует краевая супердислокация.

СТ у вершины магистральной трещины поперечного сдвига при одноосном сжатии (см. подробнее в [7]). Пусть заторможенная магистральная трещина поперечного сдвига расположена в плоскости, параллельной ДК, под действием удаленного сдвигового напряжения $\tau$. Для анализа напряженного состояния на некотором удалении от вершины такой трещины удобно использовать дислокационную модель, которая представляет трещину в виде скопления $N$ краевых дислокаций с вектором Бюргерса b. Число $N$ определяется значениями сдвигового напряжения $\tau$ и длины трещины $L$ [8]: $N=\pi(1-v) L \tau /(G b)$, где коэффициент Пуассона $v$ и модуль сдвига $G$ - осредненные эффективные упругие постоянные пористого материала с однонаправленной упаковкой длинных цилиндрических пор.

Предположим, что СТ открываются на концентраторах напряжений, которыми служат ДК, на поверхности которых растягивающие напряжения достигают максимальных значений. При этом наибольший интерес представляют ДК, расположенные рядом с вершиной магистральной трещины. В самом грубом приближении скопление краевых дислокаций, моделирующее трещину, можно представить в виде краевой супердислокации с вектором Бюргерса $\mathbf{B}=N \mathbf{b}$ [8]. Предварительный качественный анализ распределения полей напряжений вокруг такой супердислокации показал [7], что в качестве вероятных мест зарождения СТ имеет смысл рассматривать ДК, расположенные в областях „впереди“ и „под“ супердислокацией (см. вставку на рис. 3).

Для приближенного количественного анализа условий образования СТ используем решение граничной задачи теории упругости о прямолинейной краевой дислокации вблизи цилиндрической полости [9]. При таком подходе краевая супердислокация моделирует вершину трещины, в то время как полость представляет собой модель отдельного ДК. При этом влияние окружающих ДК на распределение напряжений по поверхности пробного ДК не учитывается. Последнее вполне корректно, поскольку диаметр ДК $(1-5 \mu \mathrm{m})$ существенно меньше расстояния между ними $(\sim 10 \mu \mathrm{m})$.

На рис. 3 приведены расчетные зависимости максимальных окружных напряжений на поверхности пробного ДК от расстояния $c$ между вершиной трещины (линией супердислокации) и центром этого ДК при разных его положениях (1-5) относительно супердислокации. Из приведенных зависимостей следует, что при увеличении расстояния между ДК и вершиной трещины от 7 до $13 \mu \mathrm{m}$ и при изменении угла между плоскостью залегания трещины (плоскостью скольжения супердислокации) и направлением из ее вершины на ось ДК от 0 до $90^{\circ}$ максимальные значения окружных напряжений на поверхности ДК уменьшаются. Тем не менее они остаются достаточно высокими: для полученного в эксперименте сжимающего напряжения $370 \mathrm{MPa}$ расчеты дают растягивающие напряжения от $\sim 200-800 \mathrm{MPa}$ при $c=13 \mu \mathrm{m}$ до $\sim 320-1500 \mathrm{MPa} \mathrm{при} c=7 \mu \mathrm{m}$ для ДК $1-5$ (рис. 3). Представляется, что таких напряжений более чем достаточно для зарождения СТ в образце дентина с характерным модулем Юнга порядка $2 \mathrm{GPa}$ [1]. Определив, где на поверхности ДК, ближайших к вершине трещины, действуют максимальные растягивающие окружные напряжения, можно предсказать места и направления раскрытия СТ.

В ходе проделанной работы установлено, что метод микротомографии с использованием СИ позволяет визуализировать ориентацию ДК в образцах дентина объемом в несколько кубических миллиметров без разрушающих воздействий. Прямое наблюдение подтверждает связь отклонений траекторий распространения микротрещин с присутствием ДК. Выявлен механизм торможения микротрещин в дентине путем их отклонения и расщепления. Впервые разработана количественная модель развития микротрещин поперечного сдвига путем зарождения СТ на ДК у вершины магистральной трещины.

\section{Благодарности}

Авторы благодарны Д.В. Зайцеву за предоставление образцов.

\section{Финансирование работы}

Экспериментальные исследования выполнены Т.С. Аргуновой при поддержке Российского фонда фундаментальных исследований (грант № 19-29-12041 мк). М.Ю. Гуткин благодарит Российский фонд фундаментальных исследований (грант № 18-38-20097) за под- 
держку разработки теоретической модели разрушения дентина.

\section{Конфликт интересов}

Авторы заявляют, что у них нет конфликта интересов.

\section{Список литературы}

[1] Зайцев Д.В., Григорьев С.С., Панфилов П.Е. Природа прочности дентина и эмали зубов человека. Новосибирск: Изд-во СО РАН, 2017. $173 \mathrm{c}$.

[2] Nalla R.K., Kinney J.H., Ritchie R.O. // Biomaterials. 2003. V. 24. P. $3955-3968$.

[3] Koester K.J., Ager J.W., III, Ritchie R.O. // Biomaterials. 2008. V. 29. P. $1318-1328$

[4] Palamara D., Palamara J.E.A., Tyas M.J., Messer H.H. // Dental Mater. 2000. V. 16. P. 412-419.

[5] Kinney H., Gladden J.R., Marshall G.W., Marshall S.J., So J.H., Maynard J.D. // J. Biomech. 2004. V. 37. P. 437-441.

[6] Nesterets Y.I., Gureyev T.E., Dimmock M.R. // J. Phys. D: Appl. Phys. 2018. V. 51. P. 115402(1-21).

[7] Gudkina Z.V., Argunova T.S., Gutkin M.Yu. // J. Phys.: Conf. Ser. 2019. V. 1410. P. 012066(1-6).

[8] Хирm Джс., Лоте И. Теория дислокаций. М.: Атомиздат, $1972.600 \mathrm{c}$.

[9] Dundurs J., Mura T. // J. Mech. Phys. Solids. 1964. V. 12. P. $177-189$. 